\title{
Concepções de pobreza dos atores sociais na política de assistência social no período FHC
}

\author{
Reinaldo Nobre Pontes \\ Universidade da Amazônia (Unama)
}

Concepções de pobreza dos atores sociais na política de assistência social no período FHC

Resumo: O presente artigo apresenta parte dos resultados e análises da pesquisa ${ }^{1}$ sobre as concepções de pobreza de atores sociais atuantes em políticas de combate à pobreza (Programa Comunidade Solidária e Política de Assistência Social) durante os governos Fernando Henrique Cardoso (FHC). A metodologia incluiu pesquisa bibliográfica, documental e de campo, utilizando entrevistas e grupos focais com sujeitos significantes (políticos, gestores públicos, líderes da sociedade civil e especialistas), para chegar ao conceito de pobreza entre as diferentes categorias estudadas. O estudo demonstrou a predominância de continuidades de concepções conservadoras, mas também identificou, principalmente entre alguns gestores, especialistas, líderes e políticos de esquerda, a apreensão de concepção politicamente mais avançada sobre o fenômeno da pobreza.

Palavras-chave: pobreza, desigualdade, assistência social, cidadania, combate à pobreza.

Concepts of Poverty among Social Actors in the Social Assistance Policy in the Fernando Henrique Cardoso Government

Abstract: This article presents part of the results and analyses of a study about the concepts of poverty held by social actors active in policies to fight poverty (The Solidarity Community Program and the Social Assistance Policy) during the government of Fernando Henrique Cardoso. The methodology included bibliographic, documental and field research, using interviews and focus groups with significant subjects (politicians, public administrators, civil society leaders and specialists), to arrive at an understanding of the concept of poverty found among the different categories studied. The study demonstrated the predominance of continuities of conservative concepts, but also identified, principally among administrators, specialists, leaders and lefitist politicans, the apprehension of a politically more advanced understanding of the phenomenon of poverty.

Key words: poverty, inequality, social assistance, citizenship, fighting poverty. 


\section{Introdução}

A América Latina se constitui num espaço privilegiado de observação dos perversos efeitos das políticas neoliberais que foram sentidos na qualidade de vida das classes sociais mais pobres (SALAMA, 1999). Os efeitos das políticas neoliberais provocaram piora progressiva nas condições de vida, em razão da virulência das mudanças no mercado de trabalho e nas políticas de garantias de direitos sociais (LAURELL, 2002; SADER; GENTILI, 1995; SOARES, 2001).

As políticas públicas também sofreram a sua quota de retrações de financiamento, com a disseminação, por parte das agências multilaterais, de uma "nova e avançada" metodologia de enfrentamento dos efeitos perversos da globalização, o que redundou no desdobramento de uma "cruzada" para "combater" a pobreza extrema no planeta (POGGE, 2004; PNUD, 2001).

O caso brasileiro é peculiar na América Latina porque o Brasil foi o último dos países do continente americano a capitular ante a onda do pensamento único, desdobrando as suas reformas estruturais somente nos anos 1990 (SOARES, 2000). Esse processo de globalização chega ao Brasil coincidindo com a transição do período ditatorial para redemocratização, nos anos 1980, período em que ocorre um dos piores ciclos econômicos de sua história, beirando, inclusive, a hiperinflação. Tal situação pôs fim ao longo ciclo desenvolvimentista, iniciado nos anos 1940 (BAUMANN, 1999; TOURAINE, 2000). Entretanto, estava, paradoxalmente, em curso no país uma importante mudança político-normativa, encabeçada pelo movimento de redemocratização, com base na coalisão entre as forças liberais democráticas, socialistas e nos movimentos sociais. Essa mudança arregimentou forças suficientes para aprovar uma nova constituição em 1988, com marcadas influências dos fundamentos de Estado de bem-estar europeu, resistindo a onda neoliberal mundial.

A contradição interna, gerada por uma ordem legal em conflito com a ordem econômica, pôs estes dois mundos em permanente confronto, decorrência que pautaria a década de 1990 , quando se instalam, profundamente, as recomendações do Consenso de Washington. É justamente nesse decênio quando acontece o choque entre os dois modelos, que se fundamenta a hipótese da presente pesquisa, com o cruzamento destes dois vetores sócio-políticos, no ambiente das políticas sociais, destinadas ao "combate" à pobreza. Buscamos, pois, compreender os dois polos e qual deles predominou no quadro conceitual sustentador dessas políticas sociais.

\section{Metodologia}

Assim, em meio a esse contexto, emerge o objeto deste estudo, que se situa no grande tema das políticas públicas de assistência social. Neste recorte, focalizou-se o estudo das mudanças conceituais sobre a pobreza e da assistência à pobreza no Programa Comunidade Solidária (PCS) e na Política Nacional de Assistência Social (PNAS), desenvolvidos nos governos de Fernando Henrique Cardoso (1995-1998 e 1999-2002).

Os sujeitos da investigação são os atores sociais: gestores dos programas citados; líderes da sociedade civil envolvidos com a gestão, controle social ou a execução de ações diretas com os assistidos; especialistas em assistência social, pobreza e cidadania e, por último, políticos (deputados e senadores) de direita e de esquerda, envolvidos com o tema da pobreza e da assistência social. Através de entrevistas, grupos focais, coletas de documentos oficiais e visitas institucionais, levantamos os dados fundamentais para o desenvolvimento da análise do fenômeno em estudo. Os temas para análise foram extraídos da comparação entre os discursos, de suas coincidências e contradições.

A hipótese de trabalho inspirou-se na contribuição de Telles (2001) sobre a "naturalização da pobreza" no Brasil, a partir de determinantes históricas, econômicas e culturais, refletidas nos padrões normativos praticados nas políticas de assistência aos pobres.

O primeiro passo metodológico consiste na delimitação da amplitude geográfica da amostra. Decidiu-se realizar uma investigação que abarcasse o âmbito nacional e assumimos eleger programas de assistência social de âmbito federal, observando as evoluções conceituais nos atores ligados a essa esfera, tanto do próprio Estado, como os da sociedade civil, buscando entidades representativas com abrangência nacional.

Para o acercamento do fenômeno em estudo, compreendemos que seria relevante entrevistar informantes situados em distintos níveis de mediações: frente à situação da realidade social, ou seja, na esfera estatal (poder executivo e legislativo); da sociedade civil (entidades laicas, religiosas, associativas filantrópicas - e combativas).

Foram realizados os seguintes procedimentos metodológicos em face das categorias de sujeitos: gestores (7 entrevistas e 3 grupos focais); líderes da sociedade civil (3 entrevistas e 1 grupo focal); expertos (8 entrevistas) e políticos (6 entrevistas), totalizando 24 entrevistas e 3 grupos focais. A coleta dos documentos oficiais dos programas eleitos foi feita durante as visitas às entidades governamentais e não governamentais em Brasília, São Paulo e Rio de Janeiro. O critério de seleção do corpus documental para a análise obedeceu 
aos critérios de temáticas eixo, fonte oficial, pertinência temporal e gênero de publicação.

A sistematização dos dados e a análise dos discursos foram realizadas e fundamentadas no estabelecimento de unidades de análise, dentro do marco histórico-institucional, definido na investigação e palavras-chave (DUVERGER, 1996). No nível das categorias, tomamos como referência o mesmo autor, destacando do conteúdo abordado pelos autores, "temas tratados", "tomada de posição", com respeito aos assuntos em foco (LESSARD-HEBERT; GOYTTE; BOUTIN, 1990).

Cabe esclarecer que os dados deste estudo resultaram da pesquisa realizada para elaboração de minha tese de doutoramento (PONTES, 2007), apresentada ao Departamento de Sociologia 1 (Cambio Social) no programa de doutorado Dinámicas sociales en las sociedades contemporaneas, da Universidade Complutense de Madrid/Espanha e que o projeto foi validado em seu aspecto científico e ético através da aprovação no exame do Diploma de Estudios Avanzados (DEA). E, ainda, durante o processo de execução da pesquisa, foram observadas as normas legais e éticas para pesquisa que envolve seres humanos, garantindo-se o prévio consentimento dos sujeitos envolvidos, a confidencialidade e a privacidade de seus depoimentos, inclusive a não utilização das informações em prejuízo dos que participassem da pesquisa.

\section{Pobreza: algumas tendências no debate conceitual}

Na época do feudalismo, a pobreza era compreendida quase como o resultado da "má sorte" de não pertencer à nobreza, ou de não estar sob a proteção (ou tirania) de um senhorio forte, ou, ainda, de não estar bem situado em uma corporação ou ofício. A preocupação pela pobreza ficava a cargo das ações das ordens religiosas. A mobilidade social quase não existia e as posições sociais tinham um caráter de "vontade divina".

Já no processo da passagem do ancien régime para o capitalismo, essa noção de pobreza sofre uma profunda mudança e passa a referir-se à posição em reação ao trabalho. A noção de pobreza, compreendida como uma "vontade de Deus", sofre uma alteração e passa, então, a ser entendida como o "não cumprimento da ética do trabalho". Essa ética consistia em dois simples princípios, a saber: primeiro, "se se quer conseguir o necessário para viver e ser feliz, deve-se fazer algo que os demais consideram valioso e merecedor de um pagamento; [...] segundo, que não é honesto descansar; trabalhar é um valor em si mesmo" (BAUMAN, 2000, p. 17).

A partir dessa perspectiva ética, fica claro, então, que a pobreza nascia de "não-trabalhar" e a solução radicava-se na inserção no trabalho. No capitalismo nascente, o processo de industrialização foi gradualmente expandindo-se, mas não foi capaz de absorver toda aquela mão de obra liberada da servidão feudal. Daí resultaram grandes contingentes de miseráveis sem trabalho, nem assistência.

Assim, pode-se deduzir que os pobres tinham, nessa realidade europeia do nascente capitalismo, uma função na "nova ordem social", ou seja, os pobres "bons" ou "merecedores" deviam constituir-se em mão de obra pronta para poder integrar-se à produção. Enquanto aos "maus", a nascente sociedade industrial reservava toda sorte de escárnios: "A mendicidade estava severamente castigada e a vagabundagem, em caso de reincidência, era considerada uma infração capital" (POLANYI, 1989, p. 151).

Diferentemente do período fundamentado na poor law, que garantia o "direito à vida", o utilitarismo e o liberalismo nascentes propugnavam: "a fome domesticará os animais mais ferozes, ensinará aos mais perversos a decência e civilidade, a obediência e a sujeição" (POLANYI, 1989, p. 190191). Deixar os pobres "ao léu”, sem proteção "paternalista", os levaria "naturalmente, ao caminho da normalidade do trabalho". Essa visão liberal e utilitarista da pobreza ressalta a falta de recursos à época em que se ampliara a formação de mão de obra para a nascente indústria.

Quando se trata de definir entre quais concepções de pobreza gira, atualmente, o debate, pode-se afirmar que, basicamente, dá-se entre duas correntes: os que creem que esse problema radica-se essencialmente em "causas individuais" (moralizante); e os que, ao revés, acreditam que o problema emerge da "estrutura social", resultado da desigualdade social típica do capitalismo.

Como base da primeira corrente, o individualismo nasce da concepção de que a sociedade constitui-se de um agregado de indivíduos livres e iguais, que buscam satisfazer seus desejos e preferências e que se, nessa corrida, não logram um nível aceitável de sobrevivência, tornam-se pobres, chegando, inclusive, até a exclusão social. Como regra geral, devem se queixar de si mesmos, pois não foram capazes de ser "vencedores" na "justa" competição de mercado. Pertence a essa corrente também a concepção de que assistir aos "perdedores", através de "políticas sociais" que lhes garantam "direitos sociais", leva, justamente, à situação inversa. Um dos argumentos mais fortes que os neoliberais costumam utilizar contra a ideia de assistir aos pobres e excluídos, através de políticas de garantias de direitos de cidadania, é que geram uma "cultura de dependência" ou como se costuma chamar "ardil da pobreza" (GANS, 1995; MORENO, 2000).

Atkinson, cujos conceitos vêm sendo amplamente utilizados na medição de bem-estar e pobreza, re- 
alça em sua definição de pobreza o critério de "renda", destacando que

[...] perda social que está relacionada com a distribuição desigual de renda em termos de carências de renda equivalente. Mede a desigualdade de uma distribuição de renda pela redução porcentual da renda total que pode sustentar, sem que diminua o bem-estar social (ATKINSON, 1989 apud SEN, 1999b, p. 113).

Para ele, os pobres são aqueles cujos recursos se situam abaixo de certo nível, cuja determinação depende da forma concreta em que a sociedade o concebe. Como os indivíduos utilizam seus recursos não é relevante, já que uma pessoa não é considerada pobre se tiver os meios suficientes para escapar da pobreza, sejam quais forem as condições de vida observadas.

\section{Políticas de "combate" à pobreza nos governos FHC}

A ascensão de FHC à presidência do Brasil, obedeceu, do ponto de vista político, a determinações de um processo de superação de uma crise de hegemonia das elites dominantes no país, galvanizando as forças do centro e da direita política, na implementação de um novo padrão de desenvolvimento, ancorado na liberalização e internacionalização da economia. É inegável que, durante os governos FHC, foi perseguida, com veemência, a superação do modelo varguista (trabalhista), com a instauração de um modelo de clara inspiração neoliberal.

Farias (2002) faz uma clara delineação do que chama de plano "de desenvolvimento social" do governo FHC que se estruturaria sob os seguintes conceitos: a estabilidade macroeconômica, a austeridade fiscal e a reforma do Estado.

O carro chefe desta política foi o Plano Real, plano de estabilização da moeda, que, em essência, objetivava derrubar as taxas de inflação, que haviam resistido a todos os anteriores planos. Criou uma nova moeda, o Real, que conseguiu, imediatamente depois de sua implantação, baixar a inflação de $48 \%$ para $8 \%$, em um mês. Este plano, lastreado pelas medidas propostas pelo Consenso de Washington para os países capitalistas periféricos, estabeleceu as seguintes metas: estabilização da moeda; privatização das empresas estatais; redução do papel regulador do Estado; saneamento da dívida pública; desregulamentação do mercado de trabalho; redução do financiamento público das políticas sociais, mediante corte de despesas públicas na área social.

Os efeitos distributivos do plano de estabilização, conquanto efetivos, cessaram prematuramente. Ro- cha (2000) mostra que, em setembro de 1996, estes efeitos já se igualavam aos valores alcançados no início da aplicação do plano e que o número de pobres, caiu entre 1993 e 1995, tornando, porém, a subir entre 1996 e 1998, de 25\% para $28 \%$.

O desafio do governo FHC, no tocante a políticas públicas de enfrentamento à pobreza parecia residir em duas frentes: no êxito do Plano Real e nas políticas de combate à pobreza. A alternativa adotada pelo governo para enfrentar esse quadro de agravamento da exclusão social foi buscar o caminho da contrarreforma do Estado, negadora da nova tendência legal social-democrata, de inspiração europeia, de implantação de políticas sociais universais. Retrocedendo, assim, ao substituir a velha fórmula clientelista e focalista, com a criação do Programa Comunidade Solidária (PCS), enquanto desconsiderava todo o sistema institucional de assistência social previsto na Constituição Federal e regulamentado pela Lei Orgânica da Assistência Social (LOAS).

O PCS foi criado em janeiro de 1995 como uma grande estratégia de articulação de vários programas sociais situados em vários ministérios, sob a presidência da esposa do Presidente da República. Essa estratégia dominou o primeiro governo. Com seu claro fracasso, no segundo governo a estratégia PCS é substituída pelo Programa Comunidade Ativa (PCA) e pela ativação da Política Nacional de Assistência social (PNAS).

Tais políticas e programas, cujos detalhamentos não cabem neste espaço, constituem-se espaços propícios para a análise dos discursos sobre a noção de pobreza dos diferentes atores sociais neles envolvidos.

\section{Concepções dos atores sociais sobre pobreza: continuidade versus descontinuidades}

Apresentaremos aqui uma síntese dos resultados do estudo realizado com atores sociais gestores dos programas citados; líderes da sociedade civil envolvidos com a gestão, controle social ou execução de programas socias; especialistas em políticas sociais, assistência social, pobreza e cidadania e políticos de direita e de esquerda, envolvidos com o tema da pobreza e da assistência social. E, para efeito de ilustração, algumas falas serão citadas. Os informantes responderam basicamente a perguntas abertas sobre quais mudanças observavam nas políticas sociais contra a pobreza e o que perceberam depois do advento da Constituição de 1988, e, especialmente, com relação às noções de pobreza.

Para os gestores (PCS/PNAS), o conceito de pobreza apareceu de diferentes modos no discurso dos informantes. Vamos notar importantes mudanças nas várias posições ante os anteriores modelos 
de análise de políticas socioassitenciais. No entanto, foram também percebidas linhas de continuidade em comparação com os mesmos padrões refletidos nas políticas concretas, para além do discurso governamental, que parece definitivamente modernizado por incorporar noções mais avançadas de pobreza e de cidadania ativa.

Entre os membros entrevistados do PCS, podese identificar avanços conceituais, quanto à noção de pobreza, como observamos nos textos seguintes:

[...] A pobreza hoje ganhou uma dimensão política, [...] ganhou a sociedade (Assessora do PCS, Governo Federal).

Também a seguinte afirmação é ilustrativa do avanço:

[...] o próprio conceito de pobreza e desigualdade, que ficou mais amplo, mais claro como multidimensional, como uma necessidade de se quebrar de fato com o ranço tutelar (Membro da Secretaria Executiva do PCS).

Admitir a cultura tutelar da assistência já denuncia um tímido avanço.

Sobre as visões dos gestores (PNAS) concluiuse que existe a agregação de novos sentidos, como por exemplo nesta afirmação:

Pobre é aquele que, para além de não ter a renda, não tem estudo, não tem inclusão, não tem o conhecimento [...] (Gestor Superior, Secretaria de Estado de Assistência Social).

O avanço da visão de pobreza limitada à insuficiência de renda é perceptível na afirmação acima, com especial ênfase ao déficit de conhecimento, como agravante. Sem embargo, os textos, em sequência, mostram justamente o contrário. Ou seja, que o paradigma da insuficiência de renda permanece oficialmente vigente nos programas.

[...] teoricamente, se diz pobre aqui pela posse de renda. Quer dizer, o que se define oficialmente no Brasil: [...] uma renda de meio salário mínimo per capita [...] normalmente as políticas públicas são desenhadas em cima desse foco aí (Gestor Superior, Secretaria de Estado de Assistência Social).

A noção de pobre como alguém que está despossuído de seus direitos é, certamente, mais avançada do que a noção individualista, que joga sobre ele a culpa.

Em síntese, os gestores (PCS/PNAS), em relação à forma como concebem a noção de pobre e de pobreza, não se diferenciam substantivamente, por- quanto são concordes em admitir que o que prevalece é o critério de carência de renda, embora reconheçam, por sua vez, a sua insuficiência conceitual.

Quanto aos líderes de ONGs laicas, pode-se perceber, com respeito ao conceito de pobreza, importantes deslocamentos conceituais. Conquanto se trate de um campo não governamental, é notável a incorporação das mudanças institucionais advindas da Constituição de 1988. Ocasião em que a participação da sociedade civil torna-se paradigmática na gestão das políticas públicas, porque se passa, de fato, a intervir no espaço público, tentando controlar, interferir, nos destinos das mesmas políticas.

Na citação a seguir, pode-se alcançar a tentativa de capturar o fenômeno da pobreza, a partir de um ponto de vista mais amplo, comparativamente ao paradigma dominante de "insuficiência de renda", quando define a pobreza no Brasil:

[...] não é apenas uma questão só de renda: é também uma questão de acesso à riqueza, conhecimento e poder [...] tem múltiplas causas: ela é regionalizada, ela tem gênero, ela é mais feminina do que masculina; [...] tem aspectos étnicos, raciais [...] (Líder de ONG laica).

Percebe-se, claramente, a incorporação, no discurso do tema do poder, raça e gênero, dimensões que têm mais a ver com a questão da desigualdade e que adensam a análise sobre a pobreza.

Para o informante ligado à ONG religiosa, o conceito de pobreza e de pobre não encontrou uma única posição consensual. Oscilou entre posturas de justificação moral para a existência dos pobres e outras que mesclam religião e política sob a noção de "sociedade injusta". Isto se pode confirmar na seguinte fala

[...] nós temos levantado a história desses homens, de cada um deles e porque estavam na rua, não eram (sic!) um monte de vagabundos, não! Eram, sim, um monte de desempregados e de famílias desestruturadas [...] (Líder de entidade religiosa 1).

O pobre é para ele um despossuído de seus direitos; responsabiliza a estrutura social e indica compromissos com mudanças sociais

[...] É um homem que trabalhou 24 anos na vida dele, contribuindo [...] sem ter a noção de que ele não precisava estar na rua, se tivesse, pelo meno, a consciência dos direitos que tem (Líder de entidade religiosa 1).

Por outro lado, um informante de outra entidade religiosa nacional, define o pobre como 
[...] em essência é um enfermo, do corpo que está faminto (sem calorias, sais minerais etc.), da mente (por estar fixado no lado dark da vida) e é um enfermo social (não sabe ler, escrever, não é uma criatura produtiva para a sociedade). É um enfermo moral (porque seus padrões éticos são muito baixos) (Líder de entidade religiosa 2).

Pode-se dizer também da definição supracitada que estão centradas no indivíduo as matrizes das causas, tendo, portanto, o seu eixo na moral, ajuizando sobre as escolhas e os méritos individuais.

No caso das ONG's combativas, coincidem os informantes cuja a noção de pobreza está mais atada a problemas de natureza estrutural da sociedade do que individual. A visão de que a pobreza resulta de problemas estruturais fica demonstrada, quando é afirmado que

\begin{abstract}
A pobreza e a miséria não são causas, mas, sim, consequência de um modelo concentrador e explorador são como uma herança de um povo que [...] está secularmente marcada pela herança de um traço que vem desde os tempos coloniais [...] (Líder de ONG combativa).
\end{abstract}

A referência à causalidade da pobreza tem a ver com uma crítica ao modelo econômico vigente, que, em suma, é concentrador de riquezas e gerador de desigualdades de toda a natureza. A crítica à predominante imediaticidade na percepção do problema da pobreza, descuidando de sua ancoragem histórica, é o que se depreende da citação seguinte:

[...] continua a velha definição como sendo insuficiência de renda. A pobreza é medida pelo limite da sobrevivência, e sobrevivência é comida [...] (Dirigente de associação profissional nacional, Membro do CNAS) .

Importa destacar aqui o reconhecimento da pobreza, por parte do informante, que dá mais visibilidade (publicidade) ao fenômeno, sem, entretanto, criar-se um avanço, relativamente à percepção de que a medida do fenômeno se limita à sobrevivência, a viver somente para comer. O mais criticável, segundo o informante, é a manipulação a que o tema deu lugar, já que as medidas de pobreza passam a ser construídas sob a estrita conveniência da "disponibilidade de recursos".

Na categoria dos especialistas - em política social, assistência social e pobreza, composta por expertos das áreas de Economia, Sociologia e Serviço Social, vinculados a centros de referência em pesquisa no tema em estudo -, serão apresentadas, em sequência, as tendências predominantes, encontradas nos seus discursos.
Examinando a subcategoria dos expertos em pobreza, um duplo enfoque pode-se recolher de suas afirmativas: um, com ênfase histórico-político, interpretativo da evolução do fenômeno no país; e outro, que traduz o debate entre economistas e sociólogos sobre as formas de estudar, analisar e medir a pobreza, além de seus impactos no desenho das políticas públicas, com ênfase nas políticas de assitência social.

Primeiramente, sublinhe-se a ênfase temática entre pobreza e moralização que ocorre:

[...] quando se desconecta a questão social do seu campo conflitivo, de fato advém a despolitização e a moralização do tema (Especialista em pobreza, socióloga 1).

Como podemos perceber, a informante aponta um problema chave na análise da pobreza, sua despolitização.

A separação temático-causal entre a pobreza e o trabalho, na perspectiva da sociedade salarial, é o que enfoca a citação abaixo:

[...] porque a política perdeu seu horizonte; o horizonte era incluir na sociedade salarial e a sociedade salarial cada vez mais se esvazia... (Especialista em pobreza, socióloga 1).

Tal perda de referência sobre o lugar onde incluir os pobres em uma sociedade como a brasileira afetou, sobremodo, a forma de desenhar políticas para os pobres. É como se houvessem fechado a porta de saída da política, especialmente agora em pleno ocaso do paradigma salarial-bem-estarista. Pode-se inferir, portanto, as razões do porquê da facilidade com que o tema pobreza ficou despolitizado, naturalizado.

Os enfoques do economista experto em pobreza giraram em torno da identificação dos limites de se tomar a mensuração de insuficiência de renda como a principal referência, para estabelecer a quem se pode chamar de pobre na sociedade brasileira.

A maior parte dos economistas, mais bem consolidados na área de pesquisa sobre a pobreza, reconhece razoavelmente que pobreza não é só insuficiência de renda. [...] tais indicadores são utilizados mais por questões de limitação muito mais do que por convicção de que pobreza é só aquilo [...] (Especialista em pobreza 2, economista do IPEA).

É certo que, para alguns expertos em políticas sociais, não existem dúvidas quanto aos limites em se tomar a base conceitual sobre a pobreza, a partir da mensuração de linhas de pobreza-indigência. Assim, é pobre não somente aquele que não possui renda, mas também é pobre quem não tem acesso a bens e serviços essenciais. Na seguinte manifesta- 
ção se identifica a conceituação da pobreza como geradora de consequências para a política e para os governos e seus planos e seus orçamentos:

[...] dois grandes pesquisadores sobre pobreza que escrevem isso abertamente, [...] que para se calcular a linha de pobreza, se tentava chegar num número não muito grande de pobres. Porque se trata de calcular uma fronteira para se definir o grupo alvo majoritário para as políticas (Experto em pobreza 2, economista do IPEA).

Essa "fronteira" estabelece, perversamente, uma divisão entre os que têm direito e os que não têm, a determinados benefícios, que nesses casos referemse aos direitos de sobrevivência ou de existência.

Entre os especialistas em políticas de Assistência Social, identifica-se a crítica ao paradigma dominante de "insuficiência de renda" e a ênfase na condição multidimensional do fenômeno, visão, segundo eles, a partir da qual deve ser definida a condição de pobreza.

É um conceito fundado na sociedade de mercado [...] aliado à capacidade de consumir [...] qualquer metodologia que você use vai medir o não ter (Especialista em Assistência Social 3).

Outro enfoque conceitual importante identificado alia-se à dimensão da historicidade, já referida anteriormente pelos expertos em pobreza, e que se relaciona com a resistência à visão individualista da pobreza, porque para eles a "pobreza não é uma questão individual, mas é uma construção social" (Especialista em Assistência Social 3). Nota-se uma clara intenção de conectar a existência da pobreza com sua condicionante estrutural, buscando escapar às leituras meramente métrico-quantitativas, e, resgatando a sua dimensão política, perdida nos esforços quantificadores.

Todavia, não foi desprezada a importância de conhecer a pobreza em sua dimensão espacial, visando a uma maior efetividade no seu enfrentamento, limitado à condição de instrumento de política pública, para a erradicação da pobreza.

As condições efetivas do lugar onde as pessoas vivem, as torna mais pobres, isto é, você pode ter a mesma renda, mas, dependendo das condições do lugar, aquele terá menos ou mais possibilidades (Especialista em Assistência Social 3).

Essa observação está ancorada na experiência profissional, que mostra as diferenciações no conjunto de pobres e que o lugar onde vivem é determinante para a delimitação da severidade do problema, em face da criação de portais de seleção para a inclusão em programas sociais. Isso se conecta com a visão desenvolvida de pobreza por Sen (1999b) como baixo desenvolvimento de funcionamentos e capacidades, em que critica a concepção de pobreza como insuficiência de renda.

Na categoria dos políticos (de centro-direita e de esquerda) adotou-se como critério escolher os informantes dentre aqueles que mais tenham intervindo no tema de luta contra a pobreza, através de propostas legais.

Os políticos de centro-direita são representantes dos setores mais conservadores da sociedade brasileira. Não foi estranho encontrar, entre as suas concepções, as formas mais limitadas e instrumentais de ver a pobreza e os pobres.

[...] os pobres são geralmente não-brancos [...] dois terços deles estão no Nordeste - mais da metade na zona rural. Sabemos quantos são, onde estão e como vivem (Político de direita 2, PFL).

A pobreza é reconhecida amplamente como um fenômeno complexo que vai além dos índices de renda monetária. [...]. A condição rural ou urbana destas populações também afeta o nível efetivo de bemestar dessas populações (Político de direita 1, PFL).

O problema da pobreza, segundo essa visão, não é o seu desconhecimento, nem a sua localização geográfica e regional, mas de outra natureza. Nessa definição, pode-se reconhecer a feição do perfil racial da pobreza, além da já referida feição regional, também ressaltada por outros informantes de outras categorias, o que, até mesmo, registra uma crítica implícita às definições com base exclusiva em renda, conferindo relevância à possibilidade de acesso a bens e serviços públicos.

Pode-se verificar, em síntese, nos discursos dos políticos de direita sobre a pobreza, que se modernizaram quanto ao reconhecimento do fenômeno e seu caráter social e não natural. No entanto, tais avanços conceituais ficam reduzidos, em sua capacidade de provocar mudanças, quando são aplicados em governos sob o controle de partidos de centro-direita, como se constatou nas políticas do governo FHC.

Os resultados sobre os políticos de esquerda podem ser verificados nas citações seguintes, onde se observa, quanto ao conceito de pobreza, um avanço, nos aspectos assinalados anteriormente, em relação ao discurso dos políticos de direita, uma vez que investem contra o "calcanhar de Aquiles" do discurso direitista-liberal. Ou seja, os políticos de esquerda criticam diretamente os padrões de desigualdade de riqueza e renda, consequências do desigual acesso às riquezas na sociedade capitalista. A defesa da propriedade é o limite dos avanços dos liberais conservadores. 
A afirmação de que a pobreza no Brasil é a expressão da desigualdade na distribuição da renda é um avanço em termos de concepção e de formulação; demonstramos que a nossa história econômica está marcada exatamente por um padrão de crescimento, de acumulação de riquezas e de capital, que levou a uma concentração muito grande da riqueza (Político de esquerda 4, PT).

Um eixo de análise identifica e crítica o conceito de pobreza predominante antes da Constituição de 1988, como algo atado à assistência:

[...] antes a pobreza era muito centrada na questão assistencial, era o assistencialismo mesmo [...] (Político de esquerda 2, PSB).

O que coincide com a crítica à postura dos políticos tradicionais que se aproveitavam eleitoralmente das camadas sociais mais pobres. Nesta linha crítica, também a noção de pobreza está baseada na insuficiência de renda, como confirma a declaração seguinte:

A pobreza é mais do que a falta de alimentos; [...] é a falta de acesso à educação, à infraestrutura urbana, à habitação popular, ao saneamento básico, à cultura, a uma boa educação alimentar [...] é muito mais complexo e não se resolve com um programa (Político de esquerda, partido de oposição 2, PSB).

Acrescente-se a esta tendência analítica uma noção muito mais avançada de pobreza trasladando-se do paradigma dominante e incorporando necessidades mais subjetivas e políticas para a definição de pobreza.

[... ] o pobre, ele é um cidadão, ele tem direito [...] se ele é servido por uma entidade social privada, é uma política de educação, eficaz, eficiente, universal, competente, sustentável, [...] esse é o primeiro tratamento $[\ldots]$ num projeto estratégico de longo prazo [...] uma reforma tributária para [...] uma reforma agrária pra valer (Político de esquerda 2, PSB).

Pode-se notar na declaração anterior a presença de dois importantes deslocamentos conceituais, ao afirmar a sua titularidade (ainda que potencial) de direitos, a sua condição de cidadania, que lhe confere direitos a ser bem acolhido nos serviços (públicos ou privados). Outro importante dado é afinidade da pobreza que passa por mudanças estruturais na sociedade, o que coincide com a programática reformista de viés partidário programático do informante.

Pobreza, entendida como não participação nos frutos da produção social de riqueza, introduz não só uma dimensão histórica do fenômeno, mas também uma perspectiva progressiva do problema, evitando as consequentes propostas imediatistas e assistencialistas, que nada mais fazem senão perpetuar a si mesmas.

\section{Aproximações conclusivas}

Os resultados da investigação permitiram-nos chegar a algumas conclusões provisórias que passamos, resumidamente, a relatar, valendo ressaltar o seu caráter tendencial, em nada absoluto.

Observamos se dois blocos não homogêneos de forças que se enfrentaram no direcionamento das políticas de combate à pobreza: uma conservadora $\mathrm{e}$ mantenedora de antigos padrões, que manejava a política para os pobres, como políticas eminentemente de controle dos pobres e para manutenção da ordem vigente; outra que defendia certas mudanças na direção social das políticas sociais contra a pobreza, buscando ancorá-las na noção de direito de cidadania, sob o patrocínio primacial do Estado. O primeiro bloco predominou nitidamente sobre o segundo, o que não impediu que se pudessem verificar, contraditoriamente, tendências de avanços em alguns aspectos através da análise do discurso dos atores sociais.

Constatamos que existiu certa preponderância em se conceituar a pobreza como inexistência ou insuficiência de renda, o que, a nosso juízo, implica favorecimento do predomínio da definição de acesso a programas sociais de combate da pobreza restrita à pobreza extrema. Se, pela influência do focalismo, podese encontrar uma justificativa, já sob o argumento neoliberal, que é uma forma mais eficaz de se enfrentar a pobreza, o que se constata, nesta investigação, é que o foca- 
lismo melhor serviu para limitar a compreensão da questão social e também a redução das hipóteses das políticas sociais e dos direitos que lhes dão sustentação.

Ainda que se possam reconhecer alguns avanços frente às novas modalidades de programas e projetos de ação, há, no plano conceitual, uma supremacia de concepções conservadoras, no que tange a essas modalidades de assistência pública não contributivas, o que não favorece a construção do cidadão sujeito de direitos.

Foi possível identificar, nos discursos de alguns atores, indícios de mudanças conceituais superadores de padrões mais conservadores, que apontam para a perspectiva de construção de políticas entre alguns atores, especialmente entre os acadêmicos, (não todos), políticos de esquerda e ONGs combativas. O cenário dos enfrentamentos de diferentes modelos de políticas está também envolvido em um silencioso embate teórico-político entre modelos de políticas sociais, como o que aposta em perspectivas neoliberais, reducionistas da responsabilidade do Estado, e em outra mais estatista, de inspiração socialista, ou, em sua face mais branda, liberal igualitária, mas que supõe a necessidade de uma atualização nas políticas públicas redistributivas.

\section{Referências}

BAUMANN, R. (Org.). Brasil: uma década em transição. Rio de Janeiro: Campus, 1999.

BAUMAN, Z. Trabajo, consumismo y nuevos pobres. Barcelona: Gedisa, 2000.

DUVERGER, M. Métodos de las ciencias sociales. Barcelona: Ariel, 1996.

FARIAS, V. E. Reformas institucionales y en la política de protección: coordinação gubernamental social de Brasil. Revista da CEPA, Santiago, n. 77, p. 7-24, ago. 2002.

GANS, H. J. The War Against the Poor: The Under Class and Antipoverty Policy. USA: Basic books, 1995.

LAURELL, A. C. Estado e políticas sociais no neoliberalismo. São Paulo: Cortez, 2002.

LESSARD-HÉBERT, M.; GOYETTE, G.; BOUTIN, G. Investigação qualitativa, fundamentos e práticas. Lisboa: Instituto Piaget, 1994.

MORENO, L. Ciudadanos precarios. Barcelona: Ariel, 2000.

POGGE, T. As exigências morais da justiça global. In: WERThein, J.; NOleto, M. (Org.). Pobreza $e$ desigualdade no Brasil: traçando caminhos para a inclusão social. Brasilia: Unesco, 2004, p. 241-258.
POLANYI, K. La gran transformación. Madrid: Ediciones Endymion, 1989.

PNUD-Programa das Nações Unidas para o Desenvolvimento. Informe sobre el Dessarollo Humano. Rio de Janeiro: IPEA, 2001.

PONTES, R. N. Pobreza y ciudadanía: la dialéctica de los conceptos em las políticas contra la pobreza (Brasil 19952002). 2007. 404 p. Tese (Doutorado em Sociologia) Universidad Complutense de Madrid, Madrid, 2007.

ROCHA, S. Pobreza e desigualdade no Brasil: o esgotamento dos efeitos distributivos do plano real. Rio de Janeiro: IPEA, 2000. (Texto para discussão, n. 721).

SADER, E.; GENTILI, P. (Org.). Pós-neoliberalismo: as políticas sociais e o Estado democrático. Rio de Janeiro: Paz e Terra, 1995.

SALAMA, P. Pobreza e exploração do trabalho na América Latina. São Paulo: Boitempo, 1999.

SEN, A. K. Sobre ética y economía. Madrid: Alianza Editorial, 1999a.

Nuevo examen de la desigualdad. Madrid: Alianza Editorial, 1999b.

SOARES, L. T. Os custos sociais do ajuste neoliberal na América Latina. São Paulo: Cortez, 2000. (Coleção Questões da Nossa Época, v. 78).

Ajuste neoliberal e desajuste social na América Latina. Rio de Janeiro: Vozes, 2001.

TELLES, V. S. Pobreza e cidadania. São Paulo, USP: Ed. $34,2001$.

TOURAINE, A. O campo político de FHC. Tempo Social, São Paulo: USP, v. 12, n. 2, p. 3-22, 2000.

\section{Nota}

1 Essa pesquisa foi realizada para construção de minha tese de doutorado defendida em 2007 junto ao Departamento de Sociologia 1 da Universidad Complutense de Madrid, orientada pela Prof ${ }^{a}$ Dra. María Luz Morán.

\section{Reinaldo Nobre Pontes}

reinaldopontes@ibest.com.br

Doutorado em Sociologia pela Universidade Complutense de Madrid (UCM), Espanha

Professor da Universidade da Amazônia, Pesquisador 
Coordenador do Observatório de Violências nas Escolas

\section{Universidade da Amazônia (Unama)}

Centro de Ciências Humanas e Educação

Av. Alcindo Cacela, 287

Umarizal

Belém - Pará

CEP: 66060-902 